\title{
The use of magnetic-laser therapy of patients with post- dental implant neuropathy
}

\section{Hakobyan Gagik ${ }^{1 *}$, Lazar Yesayan², Arman Seyranyan ${ }^{3}$ and Davit Matevosyan ${ }^{4}$}

${ }^{1}$ Professor, Head of Department of Oral and maxillofacial surgery, Yerevan State Medical University after M. Heratsi, Armenia

${ }^{2}$ Professor, Head of Department of Therapeutic Dentistry, Yerevan State Medical University after M. Heratsi, Armenia

${ }^{3,4}$ Assistant professor Department of Oral and maxillofacial surgery, Yerevan State Medical University after M. Heratsi, Armenia

Received: 14 April, 2019

Accepted: 22 April, 2020

Published: 23 April, 2020

*Corresponding author: Gagik Hakobyan DMSc,PhD, Professor, Head of Department of Oral and maxillofacial surgery, Yerevan State Medical University after M. Heratsi, 0028 Kievyan str. 10 ap. 65 Yerevan, Armenia, Tel: (+37410)271146; E-mail: prom_hg@yahoo.com

Keywords: Inferior alveolar nerve; Mandibular canal; Paresthesia; Dental implants; Nerve injuries

https://www.peertechz.com

Check for updates

\begin{abstract}
Objective: The aim of this study was to assess the effectiveness of magnetic-laser therapy in complex treatment of neuropathy after dental implantation

Materials and methods: The present study is based on the results of the analysis of clinical, instrumental and radiation studies of 27 patients, with post-traumatic neuropathy inferior alveolar nerve. Diagnosis of damage to the inferior alveolar nerve was based on the clinical manifestations of neuropathy (pain, paresthesia, loss of sensation, etc.). The study of the sensitivity of the skin of the lower lip and chin in the segment of the inferior alveolar nerve dysfunction and in the symmetrical segment performed using sensory tests.
\end{abstract}

Conservative treatment included: Anti-inflammatory, analgesics, antioxidants, B complex of the vitamins group. Magnetic-laser therapy included in a conservative treatment complex for patients.

To conduct a comparative analysis of effectiveness of magnetic-laser therapy, two groups were formed:

Patients first group $(n=14)$, whose treatment complex included magnetic- laser therapy,

Patients second group $(n=13)$, whose treatment complex did not include magnetic-laser therapy.

Results: Most patients after implant placement complained of pain of varying degrees, a decrease or lack of sensitivity of the lower lip, chin skin, and the mucous membrane of the alveolar process of the lower jaw, paresthesia or hyperesthesia. Some patients did not have pain, however noted that sensitivity disorders have a negative effect on general well-being and interfere with work. When comparing 2 group the best pain relief was patients first group.

The average area of skins sensory impairment in patients was mean $9.4 \mathrm{~cm}^{2}$. Patients first group complete recovered function of inferior alveolar nerve within mild 1 month, patients in the second group, whose treatment complex did not include magnetic laser therapy, fully recovered function of inferior alveolar nerve within mild 2 months.

Conclusion: Thus, the inclusion of magnetic laser therapy in the post-implantation traumatic neuropathy treatment complex allows to reduce the recovery time of functional disorders of the inferior alveolar nerve, to reduce the area of skins sensory impairment and increase the effectiveness of treatment. 


\section{Introduction}

Dental implantation, which is now widely used, is a fairly popular type of orthopedic care with partial or complete adentia. At the same time, it is known that $5 \%-26 \%$ of patients after dental implantation develop complications, accompanied by a complex of functional and structural disorders [1-6].

One of the surgical complications of dental implantation is damage to the mandibular canal during the dental implant site osteotomy or placement and postoperative indirect trauma due to hematoma, secondary ischemia and thermal stimuli [7-10].

According to various authors, the frequency of implant related Inferior Alveolar Nerve (IAN) injuries varies from 3 to $26 \%$ [11-13].

It is manifested by post-traumatic neuropathy, a characteristic clinic of pain syndrome, from mild paresthesia to complete anaesthesia, accompanied by emotional-stress disorders, and significantly worsens the patient's quality of life. The most common result of nerve damage is loss of lip, chin sensitivity [14-16]. As a result of nerve injury, many functions disturbance, such as speech, eating, and drinking, etc. Different degrees of nerve injury are available.

For assessment of the severity of inferior alveolar nerve injury, Jalbout and Tabourian classified three categories of neurosensory alterations during the implant placement (neuropraxia, axonotmesis and neurotmes) based on the dynamics of time and the completeness of restoration of sensitivity [17].

Diagnosis of IAN sensory disturbances is based on subjective clinical sensory testing and objective sensory tests. The loss sensation of the lip and chin can be measured by clinical testing [18]. Various methods of testing are used to assess neurosensory function: from patient questioning to hightech tests, however, the patient's report is the most sensitive indicator of sensory disturbances $[19,22]$.

Clinical sensory testing is still the most popular in everyday practice based upon the stimulated through cutaneous contact and includes pin tactile discrimination and thermal discrimination (war, cold)

Currently there are different treatment methods inferior alveolar nerve injury, the use of medication (vitamins $\mathrm{B}$, steroidal anti-inflammatory substances), acupuncture, local physiotherapy [23-27]. However, there is no universal therapy that contributes to the full normalization of the function of damaged nerve.

An integral part of physiotherapy include transcutaneous electric nerve stimulation, acupuncture, low level laser therapy, magneto therapy, diadynamic currents [28-31]

Magnetic therapy is considered a relatively safe alternative, without significant side effects. There are few scientific publications that evaluate the effects of magnetic-laser therapy for treatment neuropathy after implant surgery. Therefore, the effectiveness of magnetic-laser therapy in the treatment of neuropathy needs to be studied.

The aim of this study was to assess the effectiveness of magnetic-laser therapy in complex treatment of traumatic neuropathy after dental implantation.

\section{Materials and methods}

The work is based on the results of the analysis of clinical, instrumental and radiation studies of 27 patients ( 16 women and 11 men, The average age was 41.7 years), with post-traumatic neuropathy inferior alveolar nerve (axonotmesis) [17]. Diagnostic methods include objective and subjective methods, including neurosensory testing. Diagnosis of damage to the lower alveolar nerve was based on the clinical manifestations of neuropathy (pain, paresthesia, loss of sensation, etc.). During patient data collection, changes in the sensitivity of the skin of the lips and chin, of the oral mucosa were evaluated. To establish a diagnosis, radiographic examination was performed to clarify for localization implant. The final diagnosis is based on patient complaints, the results of neurosensory and Computed Tomography (CT) studies (Figure 1).

Pain levels were obtained using a visual analogue scale (VAS) (score 0-10) [32]. The VAS is presented as a 10-cm line, anchored by verbal descriptors, usually 'no pain' and 'worst pain'. The VAS is a validated, subjective measure for pain. The values can be used to track pain for a patient or to compare pain between patients with similar conditions.

Patients who presented with a complaint of pain were asked to record pain scores via a paper VAS to indicate pain intensity. Patients were instructed that a score of 1 to 3 was indicative of mild pain, 4 to 6 was indicative of moderate pain, and 7 to 10 was indicative of severe pain (Figure 2).

The study of the sensitivity of the skin of the lower lip and chin in the segment of the mandibular nerve dysfunction and in the symmetrical segment performed using sensory tests.

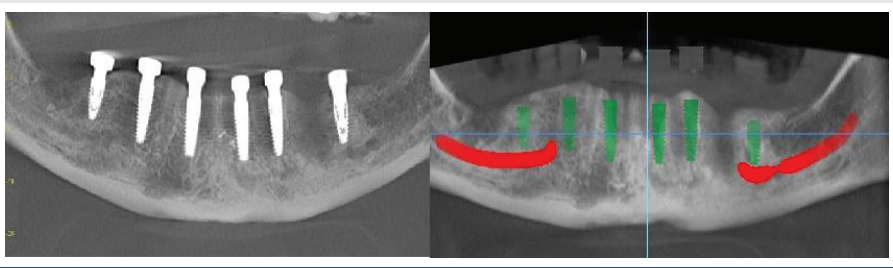

Figure 1: CT scan after surgery, nerve pressure with left distal implant.

0-10 NUMERIC PAIN RATING SCALE

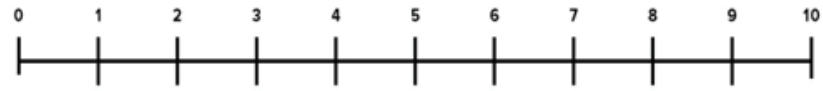

NONE MILD SEDERATE SERE

Figure 2: Pain levels visual analogue scale (VAS)

Citation: Gagik H, Yesayan L, Seyranyan A, Matevosyan D (2020) The use of magnetic-laser therapy of patients with post-dental implant neuropathy. J Nov Physiothe Phys Rehabil 7(1): 009-012. DOI: https://dx.doi.org/10.17352/2455-5487.000068 
The nature, location, prevalence, intensity, duration and frequency of pain were evaluated. The response to pain (needle puncture), thermal (hot water tube) was assessed, quantitative assessment of the area of paresthesia of the skin (Figures 3,4).

For monitoring of the IAN sensory function recovery neurosensory disorder surface area was mapping and photographing to compare with the dynamics of treatment (Figure $5 \mathrm{~A}, \mathrm{~B}$ ).
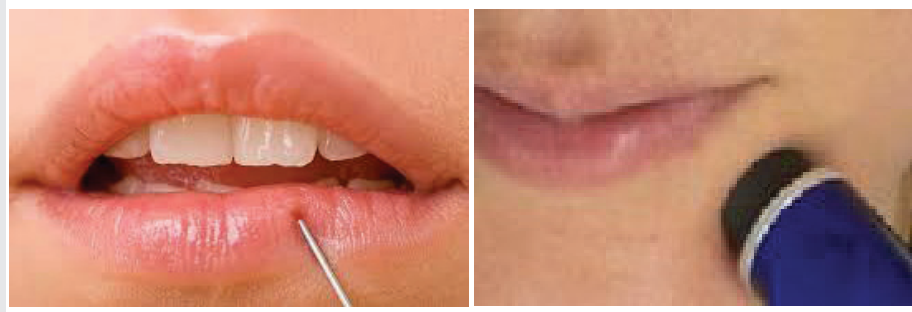

Figure 3,4: The sensitivity of the skin of the lower lip and chin performed using needle puncture and thermal (hot water tube) sensory tests.

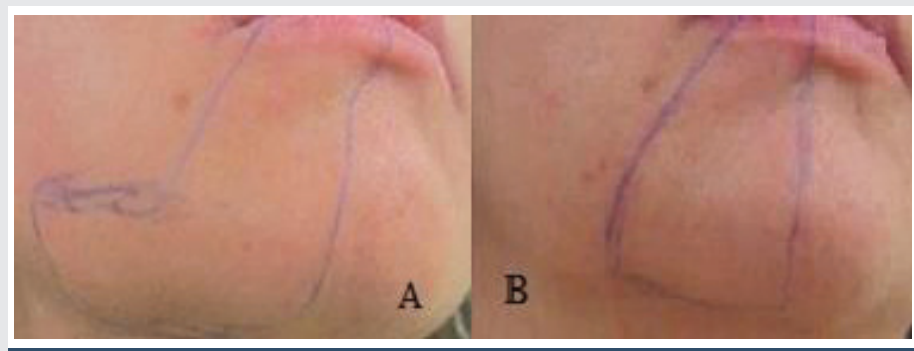

Figure 5: Sensitivity surface area was mapping and photographing(A), surface decreased after 14 days treatment compare with treatment start(B).

Factors have been identified that exacerbate or weaken the expression of sensory disturbances or pain syndrome.

All patients carried out skin sensory tests. As a result of the analysis of sensory test indicators, the degree of damage of inferior alveolar nerve and the treatment strategy were determined.

The complex of post-traumatic neuropathy treatment measures included:

- elimination of nerve compression and inflammatory processes,

- restoration of nerve trophism,

- $\cdot$ stimulation of regeneration,

The inclusion criteria for including patients in this study were post-implantation neuropathy associated with postoperative indirect trauma due to hematoma or secondary ischemia.

The exclusion criteria for patients in this study were postimplant neuropathy associated with damage to the mandibular canal during osteotomy at the site of the dental implant or implant placement.
To conduct a comparative analysis of effectiveness of magnetic laser therapy, patients were randomly assigned into two groups:

Patients first group $(n=14)$, patients received irradiation of a Magneto- Laser therapy,

Patients second group $(\mathrm{n}=13)$, whose treatment complex did not include magnetic-laser therapy.

Mean pain scores VAS scale and the mean area of sensory skin were obtained 1,2,3,4,5,6 weeks after surgery and were compared in the dynamics of treatment between the two groups.

Conservative treatment included: anti-inflammatory, analgesics, antioxidants, B complex of the vitamins group. For internal use is prescribed neurorubine (B1, B6, B12) once a day for 3 weeks, ibuprofen $600 \mathrm{mg}$ three times a day for 3 weeks, Oral dexamethasone $4 \mathrm{mg} 2$ tablets AM for 3 days and 1 tablet AM for next 3 days, in case of pain, Ketonal Forte $100 \mathrm{mg}$ of to take 1-2 tablets per day.

Magnetic-laser therapy included in a conservative treatment complex for patients. Magnetic-laser therapy was performed using the Milta-F-8-01 device (Space Equipment GAM, Russia, Figure 6).

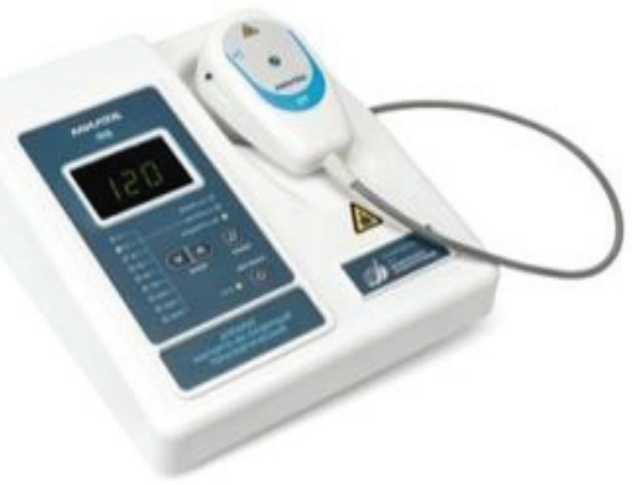

Figure 6: Magnetic-laser therapy device Milta-F-8-01

The Milta-F-8-01 device includes low-intensity pulse lasers, a magnetic field generator, low-intensity laser radiation, and a combined physiotherapeutic effect of the magnetic field. The following parameters were selected for the treatment: pulsed wave frequency $80 \mathrm{~Hz}$, wavelength $0.89 \mu \mathrm{m}$, radiation power $1.2-5 \mathrm{~mW} / \mathrm{cm}^{2}$, magnetic field is $5-10 \mathrm{mTl}$, for 5 minutes.

Magnetic-laser therapy was carried out for 10-14 days, intraoral and extraoral method in the projection of the inferior alveolar nerve and mental foramen (Figures 7, 8).

The irradiation points were established following the protocol recommended at the Special Laboratory of Lasers in Dentistry (LELO). 

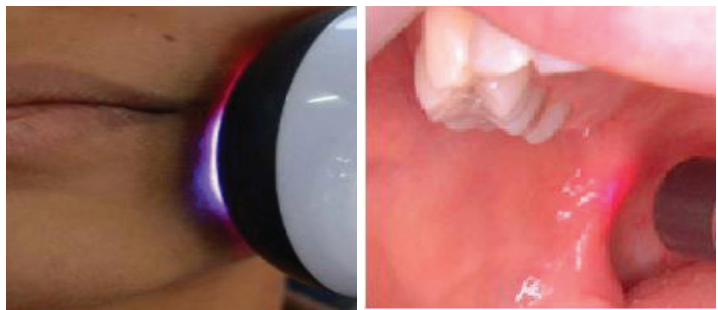

Figure 7,8: Extraoral and intraoral magnetic-laser therapy in the projection of the inferior alveolar nerve.

\section{Results}

Most patients after implant placement complained of pain of varying degrees, a decrease or lack of sensitivity of the lower lip, chin skin, and the mucous membrane of the alveolar process of the lower jaw, paresthesia or hyperesthesia. 9 patients ( 5 patients first group, 4 patients second group) did not have pain, however noted that sensitivity disorders have a negative effect on general well-being and interfere with work. Patients with pain syndrome noted a significant change in quality of life and irritability.

The relation of distribution of pain has shown that 11 patients (6 patients first group, 5 patients second group) reported mild pain (1 to 3 score), and 7 patients ( 3 patients first group, 4 patients second group) reported moderate pain ( 4 to 6 score) scores VAS.

In 6 patients first group with mild pain (1 to 3 VAS score) pain decreased and disappeared after mean 8,2 day, in 3 patients first group, with moderate pain ( 4 to 6 VAS score) pain decreased and disappeared after mean 12,4 day. In 5 patients second group with mild pain (1 to 3 VAS score) pain decreased and disappeared after mean 13,6 day, in 4 patients second group, with moderate pain ( 4 to 6 VAS score) pain decreased and disappeared after mean 18,3 day. When comparing 2 group the best pain relief was patients first group.

The average area of skins sensory impairment in patients was mean $9.4 \mathrm{~cm}^{2}$. Analysis of the results showed that the timing of the restoration of sensitivity correlated with the use of magneto-laser therapy. Patients first group complete recovered function of inferior alveolar nerve within mean 1 month, in patients second group, whose treatment complex did not include magnetic laser therapy,fully recovered function of inferior alveolar nerve within mean 2 months (diagram 1).

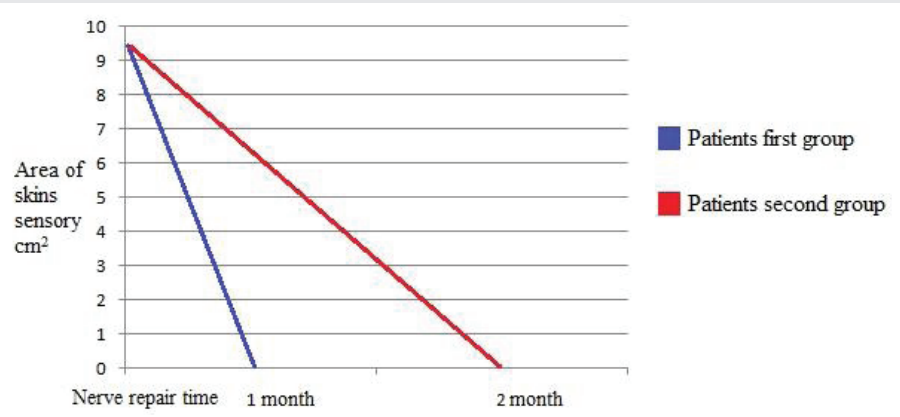

\section{Discussions}

The Inferior Alveolar Nerve (IAN) carries general sensation for the mouth, teeth, lip and chin and serve important function for oral health and general functions such as eating, chewing, tasting, and phonation [33].

Inferior alveolar nerve damage can occur during various dental surgical procedures (wisdom tooth extraction, reconstructive surgery on the lower jaw, orthognathic surgery, surgical removal of cysts, inferior alveolar nerve lateralization, dental implant placement) [34-38]. The development of these complications can be an important factor in reducing the quality of life. One of the problems dental implantology is prevention complications, development of effective methods complications.

During implant insertion different function of the inferior alveolar nerve degree disorders are caused by: direct perforation of the inferior alveolar canal, intraosseous hematoma or nerve pressure with implant. Due to a hematoma, minor injury to the IAN may develop, edema will develop later, and the injury will worsen.

In cases where the patient reports permanent numbness on the side of implant placement, including the lower lip and chin (3 hours after surgery when the effect of local anesthesia weakens), this will be the first sign of nerve damage [12].

Patient with post-traumatic trigeminal neuropathy can manifest as neuropathic pain, anesthesia, hypesthesia or hyperesthesia and the resulting stress disorder [39].

There are many possible assessment tools that are used for the assessment of nerve injury severity [40,41]. Clinical neurosensory tests (pinprick sensation, thermal sensation) were the most common reported diagnostic tests undertaken.

Any damage (penetration or compression), as well as hemorrhages in the mandibular canal lead to intraoperative pain of the neuralgic type. Ischemia itself, even without direct damage to the nerve, will cause sufficient inflammation and damage to the nerve, which can lead to permanent damage to the nerve. The degree of pain relief is individual and depends on each patient.

The issue of regeneration of nerve tissue and pathomorphological changes in the nerve fiber when it is damaged during dental implantation is discussed in research publications.

The variety of proposed treatment methods and the lack of universal tactics indicate the need to develop new methods of treatment post-traumatic neuropathy of inferior alveolar nerve.

The conservative therapies for Inferior Alveolar Nerve (IAN) neuropathy include the use of corticosteroids and nonsteroidal anti-inflammatories [41]. In the absence of effective methods to resolve post-traumatic neuropathy inferior alveolar nerve has been a recommended alternative treatment method, including physiotherapy [42-48].

Citation: Gagik H, Yesayan L, Seyranyan A, Matevosyan D (2020) The use of magnetic-laser therapy of patients with post-dental implant neuropathy. J Nov Physiother Phys Rehabil 7(1): 009-012. DOI: https://dx.doi.org/10.17352/2455-5487.000068 
Magneto-laser therapy is among the methods of physiotherapy accelerates the healing and regeneration of tissues after damage, eliminates pain and swelling. Magnetolaser field act on the molecules of cell structures, to activate the processes of metabolism of cells and the activity of enzymatic systems, stimulation of nerve cell and lymphocyte respiration. At the tissue level, there is observed: improved microcirculation, accelerated revascularization and reinnervation, decreased intracellular and intercellular edema, increased blood oxygen saturation at the microcirculatory level.

The early diagnosis and treatment of this pathology, which causes suffering to patients, seems to be an important task in implantology, in connection with the foregoing, the further development of treatment methods is reasonable and relevant.

Based on this, for the treatment of 27 patients with postimplantation neuropathy inferior alveolar nerve (axonotmesis) we included magnetic-laser therapy in the treatment complex and evaluated the results of treatment.

The Visual Snalogue Scale (VAS) pain scores for each group at each time were analyzed. Results from the study indicate that pain was reduced in both treatment groups. A reduction in the duration of pain and the terms of the restored function of the lower alveolar nerve in patients of the first group compared to patients second group shows the effectiveness of magneticlaser therapy. Effectiveness of magnetic-laser therapy on pain reduction can be explained by the fact that laser light absorbed by nociceptors, exert an inhibitory effect on A and C pain fibers, which slows conduction velocity, and suppresses neurogenic inflammation.

The results of the treatment showed that, complex treatment using magnetic-laser therapy reduced the time of restoration of sensitivity of the lips and skin of the chin also facilitated pain sensitivity and decreases increase the effectiveness of treatment. Magnetic-laser therapy promote to increase blood flow by vasodilation and also reduces edema. Thus, the inclusion of magnetic-laser therapy in the post-implantation traumatic neuropathy treatment complex allows to reduce the recovery time of functional disorders of the inferior alveolar nerve, to reduce the area of skins sensory impairment.

If the nerve is damaged, evaluation and treatment should be started immediately after the damage to get a good prognosis. Magnetic-laser therapy can be recommended as a non-pharmacological alternative in patients presenting with mild to moderate pain on the day after nerve injury, the effects related to the degree of nerve injury. Moreover, the use of magnetic laser therapy does not cause side effects and allows you to achieve a lasting long-term result.

\section{Conclusions}

Based on the developed data, it can be concluded that magnetic-laser therapy can have a positive effect on the restoration of disorders of the sensitivity of the lower alveolar nerve, accelerating the improvement of the regeneration of the affected nerves after dental implantation, increase the effectiveness of treatment.

\section{Declarations}

\section{Conflict of interest and financial disclosure}

The author declares that he has no conflict of interest and there was no external source of funding for the present study. None of the authors have any relevant financial relationship(s) with a commercial interest.

\section{Funding}

This research did not receive any specific grant from funding agencies in the public, commercial, or not-for-profit sectors.

\section{Ethics approval and consent to participate}

This protocol was approved by the Clinical Research Ethics Committee Yerevan State Medical University after M. Heratsi (protocol N16 14.05.18) and in accordance with those of the World Medical Association and the Helsinki Declaration.

\section{References}

1. Truab D (1997) Surgical complications related to implant surgery. N M Dent J 48: 16-17. Link: https://bit.ly/2VPKB8z

2. Garg AK (2004) Complications associated with implant surgical procedures part 1: prevention. Dent Implantol 15: 25-32. Link: https://bit.ly/2VJOHyl

3. Misch K, Wang HL (2008) Implant surgery complications: etiology and treatment. Implant Dent 17: 159-168. Link: https://bit.ly/3awss4E

4. Annibali S, Ripari M, La Monaca G, Tonoli F, Cristalli MP (2009) Local accidents in dental implant surgery: prevention and treatment. Int $\mathrm{J}$ Periodontics Restorative Dent 29: 325 331. Link: https://bit.ly/2KsQDqs

5. Dubois L, de Lange J, Baas E, Van Ingen J (2010) Excessive bleeding in the floor of the mouth after endosseus implant placement: a report of two cases. Int J Oral Maxillofac Surg 39: 412-415. Link: https://bit.ly/2RYznxp

6. Froum S (2010) Dental Implant Complications, Etiology, Prevention and Treatment 19: 362. Link: https://bit.ly/2RZIxtc

7. Ellies LG (1992) Altered sensation following mandibular implant surgery: a retrospective study. J Prosthet Dent 68: 664-671. Link: https://bit.ly/3cKgN3J

8. Dao TT, Mellor A (1998) Sensory disturbances associated with implant surgery. Int J Prosthodont 11: 462-469. Link: https://bit.ly/2VOrMmc

9. Nazarian Y, Eliav E, Nahlieli O (2003) Nerve injury following implant placement: prevention, diagnosis and treatment modalities. Refuat Hapeh Vehashinayim 20: 44-50. Link: https://bit.ly/3bwHRTT

10. Hegedus F, Diecidue RJ (2006) Trigeminal nerve injuries after mandibular implant placement--practical knowledge for clinicians. Int J Oral Maxillofac Implants 21: 111-116. Link: https://bit.ly/34WyRFa

11. Worthington $P$ (2004) Injury to the inferior alveolar nerve during implant placement: a formula for protection of the patient and clinician. Int $\mathrm{J}$ Oral Maxillofac Implants 19: 731-734. Link: https://bit.ly/2Ku2HYd

12. Juodzbalys G, Wang HL, Sabalys G (2011) Injury of the Inferior Alveolar Nerve during Implant Placement: a Literature Review. J Oral Maxillofac Res 2: e1 Link: https://bit.ly/2KxmzJX

13. Alhassani AA, Al Ghamdi AS (2010) Inferior alveolar nerve injury in implant dentistry: diagnosis, causes, prevention, and management. J Oral Implantol 36: 401-407. Link: https://bit.ly/3axBMFD 
14. Misch CE, Resnik R (2010) Mandibular nerve neurosensory impairment afte dental implant surgery: management and protocol. Implant Dent 19: 378-386. Link: https://bit.ly/3aqTXg1

15. Juodzbalys G, Wang HL, Sabalys G, Sidlauskas A, Galindo-Moreno P (2013) Inferior alveolar nerve injury associated with implant surgery. Clin Oral Implants Res 24: 183-190. Link: https://bit.ly/3at7Z0D

16. Dannan A (2013) Traumatic Injury of the Inferior Alveolar Nerve after Dental Implant Surgery; a Literature Review. The Internet Journal of Dental Science 12: 1-7. Link: https://bit.ly/2VsQ465

17. Jalbout Z, Tabourian G (2004) Glossary of Implant Dentistry. Proceedings of International Congress of Oral Implantologists, Upper Montclair, New Jerjey.

18. Zuniga JR, Meyer RA, Gregg JM, Miloro MD, Davis LA (1998) The accuracy of clinical neurosensory testing for nerve injury diagnosis. J Oral Maxillofac Surg 56: 2-8. Link: https://bit.ly/3bvP9Yn

19. Bouhassira D, Attal N, Alchaar H, Boureau F, Brochet B, et al. (2005) Comparison of pain syndromes associated with nervous or somatic lesions and development of a new Neuropathic pain diagnostic questionnaire (DN4). Pain 114: 29-36. Link: https://bit.ly/2Kxmiqp

20. Ylikontiola L, Vesala J, Oikarinen K (2001) Repeatability of 5 clinical neurosensory tests used in orthognathic surgery. Int J Adult Orthodon Orthognath Surg 16: 36-46. Link: https://bit.ly/2VTd0u6

21. Poort LJ, van Neck JW, van der Wal KG (2009) Sensory testing of inferior alveolar nerve injuries: a review of methods used in prospective studies. $\mathrm{J}$ Oral Max illofac Surg 67: 292-300. Link: https://bit.ly/2S1|zll

22. Siqueira SR, Siviero M, Alvarez FK, Teixeira MJ, Siqueira JT (2013) Quantitative sensory testing in trigeminal traumatic neuropathic pain and persistent idiopathic facial pain. Arq Neuropsiquiatr 71: 174-179. Link https://bit.ly/2RZTJGq

23. Park JH, Lee SH, Kim ST (2010) Pharmacologic management of trigeminal nerve injury pain after dental implant surgery. Int J Prosthodont 23: 342-346. Link: https://bit.ly/3cxQcqK

24. Sieroń A, Cieślar G (2013) The magnetic fields and light in medicine and physiotherapy. Alfa-Medica Press177-231.

25. Raso VM, Barbieri CH, Mazzer N, Fasan VS (2005) Can therapeutic ultrasound influence the regeneration of the peripheral nerves. J Neurosci Methods 142 185-192. Link: https://bit.ly/3bvjDcs

26. Fukuda K, Ichinohe T, Kaneko Y (2014) Pain Management for Nerve Injury following Dental Implant Surgery at Tokyo Dental College Hospital. Int J Dentistry Link: https://bit.ly/3cHuwIQ

27. Poole TE, Holland I, Peterson LJ (1993) Clinical Efficacy of low level laser treatment of oro-facial neurosensory deficits. J Oral Maxillofac Surg 51: 182 186

28. Ka L, Hirata H, Kobayashi A, Wake H, Kino K, et al. (2006) Treatments results of acupuncture in inferior alveolar and lingual nerves sensory paralysis after oral surgery. Kokubyo Gakkai Zasshi 73: 40-46. Link: https://bit.ly/3avncyj

29. Kasperski J, Rosak P, Rój R, Czelakowska A, Sieroń-Stołtny K, et al. (2015) The influence of low-frequency variable magnetic fields in reducing pain experience after dental implant treatment. Acta Bioeng Biomech 17: 97-105. Link: https://bit.ly/2VwozZe

30. Cieslar G, Kasperczyk S, Mrowiec J, Plech A, Puszer M, et al. (2006) Analgesic effect of simultaneous exposure to $\mu \mathrm{T}$ magnetic field and infrared radiation in rats. Pol J Environ Stud 15: 22-24. Link: https://bit.ly/3eJiZKY

31. Raso VVM, Barbieri CH, Mazzer N, Fasan VPS (2006) Effects of therapeutic ultrasound on injuries due to crushing of the sciatic nerve in rats: functional evaluation of gait. Rev Bras Fisioter 10: 113-119. Link: https://bit.ly/3bzqPEI
32. Couper M, Tourangeau R, Conrad F (2006) Evaluating the effectiveness of visual analog scales: A web experiment. Soc Sci Comput Rev 24: 227245. Link: https://bit.ly/3cE73ls

33. Zuniga JR, Renton TJ (2016) Neurol Neuromed 1: 10-14.

34. Robert RC, Bacchetti $P$, Pogrel MA (2005) Frequency of trigeminal nerve injuries following third molar removal. J Oral Maxillofac Surg 63: 732-735. Link: https://bit.ly/3awvAOC

35. Cheung LK, Leung YY, Chow LK, Wong MC, Chan EK, et al. (2010) Incidence of neurosensory deficits and recovery after lower third molar surgery:A prospective clinical study of 4338 cases. Int J Oral Maxillofac Surg 39: 320326. Link: https://bit.ly/2Y4MocF

36. Marchiori EC, Barber JS, Williams WB, Bui PQ, O'Ryan FS (2013) Neuropathic pain following sagittal split ramus osteotomy of the mandible: Prevalence, risk factors and clinical course. J Oral Maxillofac Surg 71: 2115-2121. Link: https://bit.ly/2XZ370w

37. Hillerup S (2008) latrogenic injury to the inferior alveolar nerve: etiology, signs and symptoms, and observation on recovery. Int $\mathrm{J}$ Oral Maxillofac Surg 17: 704-709. Link: https://bit.ly/2Ku70Tz

38. Kubilius R, Sabalys G, Juodzbalys G, Gedrimas V (2004) Traumatic Damage to the Inferior Alveolar Nerve Sustained in Course of Dental Implantation. Possibility of Prevention// Stomatologija, Baltic Dental Maxillofac J 6: 106110. Link: https://bit.ly/2Ks6God

39. Renton T, Dawood A, Shah A, Searson L, Yilmaz Z (2012) Post-implant neuropathy of the trigeminal nerve. A case series. Br Dent J 212: E17. Link: https://bit.ly/2KtUeEq

40. Devine M, Hirani M, Durham J, Nixdorf DR, Renton T (2018) Identifying criteria for diagnosis of post-traumatic pain and altered sensation of the maxillary and mandibular branches of the trigeminal nerve: a systematic review. Oral Surg Oral Med Oral Pathol Oral Radiol 125: 526-540. Link: https://bit.ly/3bwmwtZ

41. Teerijoki-Oksa T, Jääskeläinen S, Forssell K, Virtanen A, Forssell H (2003) An evaluation of clinical and electrophysiologic tests in nerve injury diagnosis after mandibular sagittal split osteotomy. Int J Oral Maxillofac Surg 32: 15-23. Link: https://bit.ly/2KtU4gi

42. Seo K, Tanaka Y, Terumitsu M, Someya G (2004) Efficacy of steroid treatment for sensory impairment after orthognathic surgery. J Oral Maxillofac Surg 62 : 1193-1197. Link: https://bit.ly/2yEx7nT

43. Bates JAV, Nathan PW (1980) Transcutaneous electrical nerve stimulation for chronic pain. Anesthesia 35: 817-824. Link: https://bit.ly/2KnXVeS

44. Poole TE, Holland I, Peterson LJ (1993) Clinical Efficacy of low level laser treatment of oro-facial neurosensory deficits. J Oral Maxillofac Surg 51: 182186.

45. Ozen T, Orhan K, Gorur I, Ozturk A (2006) Efficacy of low level laser therapy on neurosensory recovery after injury to the inferior alveolar nerve. Head Face Med 2: 3. Link: https://bit.ly/2zohjGs

46. Renton T, Devine M (2013) Diagnosis and management of inferior alveolar nerve damage associated with dental implant surgery. Forum Implantologicum 9: 16-27. Link: https://bit.ly/2RZFWPY

47. Bagheri SC, Meyer RA (2011) Management of mandibular nerve injuries from dental implants. Atlas Oral Maxillofac. Surg Clin North Am19: 47-61. Link: https://bit.ly/352oDTN

48. Abdelrahim A, Hassanein HR, Dahaba M (2011) Effect of pulsed electromagnetic field on healing of mandibular fracture: a preliminary clinica study. J Oral Maxillofac Surg 69: 1708-1717. Link: https://bit.ly/2Vwkvsf

Copyright: @ 2020 Gagik H, et al. This is an open-access article distributed under the terms of the Creative Commons Attribution License, which permits unrestricted use, distribution, and reproduction in any medium, provided the original author and source are credited.

Citation: Gagik H, Yesayan L, Seyranyan A, Matevosyan D (2020) The use of magnetic-laser therapy of patients with post-dental implant neuropathy. J Nov Physiother Phys Rehabil 7(1): 009-012. DOI: https://dx.doi.org/10.17352/2455-5487.000068 